University of Nebraska - Lincoln

DigitalCommons@University of Nebraska - Lincoln

1998

\title{
Chemical Attractants for Trapping Yellow jackets Vespula germanica and Vespula pensylvanica (Hymenoptera: Vespidae)
}

Peter Landolt

USDA-ARS

Follow this and additional works at: https://digitalcommons.unl.edu/entomologyother

Part of the Entomology Commons

Landolt, Peter, "Chemical Attractants for Trapping Yellow jackets Vespula germanica and Vespula pensylvanica (Hymenoptera: Vespidae)" (1998). Entomology Papers from Other Sources. 62.

https://digitalcommons.unl.edu/entomologyother/62

This Article is brought to you for free and open access by the Entomology Collections, Miscellaneous at DigitalCommons@University of Nebraska - Lincoln. It has been accepted for inclusion in Entomology Papers from Other Sources by an authorized administrator of DigitalCommons@University of Nebraska - Lincoln. 


\title{
Chemical Attractants for Trapping Yellowjackets Vespula germanica and Vespula pensylvanica (Hymenoptera: Vespidae)
}

\author{
PETER J. LANDOLT
}

USDA-ARS, 5230 Konnowac Pass Road, Wapato, WA 98951

\begin{abstract}
Environ. Entomol. 27(5): 1229-1234 (1998)
ABSTRACT Worker yellowjackets (Hymenoptera: Vespidae) were captured in traps baited with combinations of an aqueous solution of acetic acid and polyethylene caps loaded with either butyl butyrate, heptyl butyrate, or isobutanol. Vespula germanica (F.) were captured in large numbers in traps baited with acetic acid and isobutanol or acetic acid and butyl butyrate. Vespula pensylvanica (Saussure) were captured in large numbers in traps baited with heptyl butyrate, acetic acid and heptyl butyrate, acetic acid and butyl butyrate, and acetic acid and isobutanol. Acetic acid generally enhanced the attractiveness of these other compounds to V. pensylvanica and V. germanica. Vespula atropilosa (Sladen) were captured in large numbers in traps baited with heptyl butyrate or acetic acid and heptyl butyrate, with no apparent effect of the addition of acetic acid to the trap, and they were only weakly attracted to other baits. The importance of acetic acid to attraction of V. germanica and $V$. pensylvanica to these lures supports the hypothesis that this response is food-finding behavior. The chemical lure comprised of acetic acid and isobutanol can be used for trapping the worldwide pest $V$. germanica, with the added advantage of simultaneous attractiveness to $V$. pensylvanica.
\end{abstract}

KEY WORDS Vespula germanica, Vespula pensylvanica, yellowjackets, attractants, trapping

YELLOWJACKETS, SOCIAL WASPS in the genera Vespula Thomson and Dolichovespula Rohwer (Greene and Caron 1980), are serious stinging hazards to humans throughout much of the temperate areas of the world (Akre et al. 1980). Although yellowjackets are primarily predators of arthropods, some species also scavenge extensively for food. These species are particularly troublesome because their foraging brings them into frequent contact with people. Efforts to control wasp populations have focused on destruction of nests or on removal of foraging workers with poison baits or traps baited with chemical attractants or food materials. The development of yellowjacket control methods based on trapping of foragers or on the killing of colonies by the use of poisoned baits has been hampered by a lack of effective attractants for most of the primary pestiferous species.

Species of yellowjackets that scavenge for food may be attracted to both meat-based and sugar-based baits. Combinations of pesticides and meats have been used to control the western yellowjacket, Vespula pensylvanica (Saussure) (Grant et al. 1968); the common yellowjacket, Vespula vulgaris (L.) (Wagner and Reierson 1969); and the German yellowjacket Vespula germanica (F.) (Perrott 1975, Spurr et al. 1996). Yellowjackets also are attracted to sweet materials. Sweet baits also have been used with limited success in poison baits (Edwards 1977, 1980; Christie 1992; Dymock et al. 1991). Such sweet baits have not been used extensively, in part because of their attractiveness to honeybees (Spurr 1996). The effectiveness of these baits also varies geographically (Spurr 1996). Meat- based baits also are not used extensively because of their expense and the short length of time that they are attractive (Spurr 1995). Synthetic food attractants added to an inert matrix may constitute a useful bait with a long field life (Ross et al. 1984, Spurr 1995).

Chemical attractants are known for some species of yellowjackets. Davis et al. (1967) discovered attraction of $V$. pensylvanica to 2,4-hexadienyl butyrate, 2,4hexadienyl proprionate and 2,4-hexadienyl isobutyrate. Subsequent tests revealed the superior attractiveness of heptyl butyrate (Davis et al. 1969, 1973) and of octyl butyrate (McGovern et al. 1970, Davis et al. 1972) to V. pensylvanica. MacDonald et al. (1973) reported the trapping of large numbers of queens and workers of Vespula atropilosa (Sladen) and workers of $V$. pensylvanica with heptyl butyrate. These and other compounds are apparently weakly attractive or are ineffective in attracting other yellowjacket species, including the pestiferous $V$. germanica, V. vulgaris, Vespula maculifrons (Buysson) and Vespula squamosa (Drury) (Grothaus et al. 1973, Howell et al. 1974, MacDonald et al. 1973).

I report herein the attractiveness of acetic acid and isobutanol to workers of 2 species of yellowjackets, and optimum doses of isobutanol and heptyl butyrate for attractiveness to 3 different species. Small numbers of $V$. germanica and $V$. pensylvanica were initially captured in traps baited with chemicals (acetic acid, isobutanol, butyl butyrate) isolated and identified from headspace of fermented molasses (unpublished data) or jaggery, a palm sugar extract (R. Heath, personal communication). These solutions are attractive 
to many species of Lepidoptera (Landolt 1995, Landolt and Mitchell 1997) and yellowjacket attraction to isobutanol and acetic acid was discovered during attempts to develop attractants for pestiferous moths. A series of trapping tests was subsequently conducted to investigate more thoroughly the attraction of yellowjackets to these compounds. This work provides evidence of an effective chemical attractant for $V$. germanica, which is not attracted to heptyl butyrate (Spurr 1996), and provides an additional attractant for $V$. pensylianica.

\section{Materials and Methods}

Trapping experiments were conducted to evaluate chemicals as attractants for the worker caste of species of yellowjackets present in Yakima County, WA and to compare the attractiveness of these chemicals at different doses. The lst experiment evaluated heptyl butyrate, butyl butyrate, and isobutanol, with and without an acetic acid solution, as baits for yellowjackets. Heptyl butyrate was included for comparison because of its known attractiveness to $V$. pensylvanica (Davis et al. 1969). Butyl butyrate also was reported previously to be attractive to V. pensylvanica (McGovern et al. 1970). Subsequent experiments evaluated doses of isobutanol, doses of heptyl butyrate, and concentrations of acetic acid in water.

Yellowjacket Trappit Dome traps (Agrisense, Fresno, CA) were used in all experiments. All traps contained $200 \mathrm{ml}$ of a drowning solution composed of water $(200 \mathrm{ml})$, clay $(20 \mathrm{mg})$, Palmolive concentrated dishwashing liquid $(25 \mu \mathrm{l}$ ) (Colgate-Palmolive, New York), and Schilling food color ( $50 \mu$ l yellow, $25 \mu \mathrm{l}$ blue, and $60 \mu \mathrm{l}$ red) (McCormick, Hunt Valley, MD). Food dyes were added to make the color of the drowning solution similar to aged molasses solutions and clay was added to make the solution cloudy, similar to that of the aged molasses. Acetic acid was added to this solution in some treatments as an attractant. Heptyl butyrate, butyl butyrate, and isobutanol were formulated in $2 \mathrm{ml}$ polyethylene caps (No.60975D-3, Kimbel Glass, Vineland, NJ) that were pinned to the inside top of the trap.

Trap plots were near Parker Heights, near Moxee, and $24 \mathrm{~km}$ east of Moxee, all in Yakima County, WA. Traps were placed in fruit trees, windbreak trees, and on fencing, $1-1.5 \mathrm{~m}$ above ground and $\approx 10 \mathrm{~m}$ apart.

Chemical Comparison. Six chemical treatments were selected and compared with a control as baits for yellowjackets. The principal objectives of this experiment were to determine if isobutanol with acetic acid and butyl butyrate with acetic acid are attractive to $V$. germanica and $V$. pensylvanica and to compare the attractiveness of these chemicals to that of heptyl butyrate, a known chemical attractant for western yellowjackets (Davis et al. 1969). The 6 treatments were as follows: (1) $1 \mathrm{ml}$ of heptyl butyrate, (2) $1 \mathrm{ml}$ of heptyl butyrate and $0.5 \%$ acetic acid in the $200 \mathrm{ml}$ of drowning solution, (3) $1 \mathrm{ml}$ of butyl butyrate, (4) $1 \mathrm{ml}$ of butyl butyrate and $0.5 \%$ acetic acid in the 200 $\mathrm{ml}$ of drowning solution, (5) $1 \mathrm{ml}$ of isobutanol, and
(6) $1 \mathrm{ml}$ of isobutanol and $0.5 \%$ acetic acid in $200 \mathrm{ml}$ of drowning solution. The control trap contained 200 $\mathrm{ml}$ of the drowning solution without acetic acid. A randomized complete block design was used with each treatment represented per block and 10 blocks set up in 3 widely separated orchards $(8-20 \mathrm{~km}$ between orchards). This experiment was begun on 26 July 1997. Wasps were removed and counted 3 times per week and the drowning solution in the trap (with or without acetic acid) was augmented or replaced as needed due to evaporation. Captured wasps were tallied by species, sex, and caste. This experiment was maintained for $2 \mathrm{wk}$.

Data used in statistical analyses were from blocks in which $>9$ workers of a species were captured. Data for workers of V. atropilosa, V. germanica, and V. pensylvanica captured in baited traps were subjected to an analysis of variance (ANOVA), after data transformation to percentages of block totals, and treatment means were separated by the Tukey test at $\alpha=0.05$. Data for the workers of the 3 species captured in baited traps also were compared by Student $t$-test with that from unbaited traps to determine if significant numbers were trapped for each bait treatment.

Comparisons of Doses of Heptyl Butyrate and of Isobutanol. Different doses of heptyl butyrate were compared as an attractant for $V$. pensylvanica and different dosages of isobutanol were compared as an attractant for both $V$. pensylvanica and $V$. germanica. These 2 experiments were conducted using traps also containing $0.5 \%$ acetic acid in the drowning solution. A range of heptyl butyrate doses (providing a range of release rates) was obtained by varying concentrations of heptyl butyrate in mineral oil. Polyethylene caps were loaded with $1 \mathrm{ml}$ of $0,12.5,25,50,75$, and $100 \%$ heptyl butyrate (by volume) in mineral oil. A randomized complete block design was used, with 6 sets of the 6 treatments in traps placed in groves of fruit trees. Each set or block was composed of 1 each of the 6 treatments. This experiment was begun 18 August 1997. Traps were checked and randomized every $2-3$ d over $10 \mathrm{~d}$, providing 18 replicates ( 3 randomizations of 6 block replicates).

Two experiments were conducted to compare doses of isobutanol in mineral oil as an attractant for yellowjackets. The 2 nd experiment with a low dose range was employed after it was determined that the lowest dose of the 1st experiment was near optimum for capture of $V$. germanica in traps. For both experiments, isobutanol was combined with mineral oil and loaded into polyethylene caps. Caps were loaded with $1 \mathrm{ml}$ of a mixture of isobutanol in mineral oil at the following percentages by volume: $0,12.5,25,50,75$, and $100 \%$ for the 1 st test, and $0,1,2,4,8$, and $16 \%$ for the 2 nd test. For each test, a randomized complete block design was used, with 6 sets of treatments in traps placed in groves of fruit trees. Each set or block was composed of one each of the 6 treatments. Traps were checked, insects removed, and treatments randomized every $2-3 \mathrm{~d}$ over $10 \mathrm{~d}$, providing 18 replicates (3 randomizations of 6 block replicates). The high-dose test was begun 8 August 1997, and the low-dose test was begun 
26 August 1997. Trap data were transformed to percentages of block totals before analyses. Regression analyses were performed on transformed data to determine if trap catches varied with dose.

Comparison of Concentrations of Acetic Acid. Two experiments were conducted to evaluate the effectiveness of different percentages of acetic acid in water as an attractant for $V$. germanica and $V$. pensylvanica. These experiments were comparisons of 0 , $0.125,0.25,0.5,1$, and $2 \%$ acetic acid in water used to make the drowning solution, with $200 \mathrm{ml}$ of drowning solution put into each trap. In the lst experiment, all traps also were baited with a polyethylene cap containing $1 \mathrm{ml}$ of a $50 \%$ mixture of heptyl butyrate in mineral oil. Traps with these 6 bait treatments were set up in a randomized block design, with 6 blocks of traps set up at different locations. This experiment was begun 2 September 1997. Traps were checked and insects removed every 2-3 d for $1 \mathrm{wk}$. At each date, treatment positions within blocks were randomized, providing 18 replicates per treatment ( 6 blocks times 3 trap checkings). The above experiment was repeated in its entirety with caps loaded with isobutanol. The same concentrations of acetic acid in water were tested and all traps contained a cap loaded with $1 \mathrm{ml}$ of a mixture of $16 \%$ isobutanol in mineral oil. Six blocks of traps were checked every $2-3 d$ and were randomized each time they were checked. This experiment was begun 9 September 1997 and maintained for $16 \mathrm{~d}$, providing 36 replicates per treatment ( 6 blocks times 6 trap checkings).

Trap data were transformed to percentages of block totals before analyses. Regression analyses were performed on transformed data to determine if trap catches varied with concentration. All statistical procedures were conducted using the StatMost program by DataMost (1995).

\section{Results}

Chemical Comparisons. In the 1st experiment, numbers of $V$. germanica, $V$. pensylvanica, and V. atropilosa workers captured were suitable for statistical comparisons. All bait treatments resulted in captures of all 3 species of yellowjackets and no wasps were captured in unbaited traps (Table 1). Comparison of treatment means with an expected mean of zero (equivalent to the control traps) by t-test indicated that all treatment captures were significant (means differed from zero at the 5\% error level) except for captures of $V$. atropilosa in traps baited with isobutanol. However, trap catches varied with chemical treatments and differences among chemical treatments varied with yellowjacket species. Large numbers of $V$. germanica were captured in traps baited with butyl butyrate plus acetic acid or isobutanol plus acetic acid (Table 1). Isobutanol plus acetic acid was the most attractive treatment by far for $V$. germanica. Large numbers of $V$. pensylvanica workers were captured in traps baited with heptyl butyrate, heptyl butyrate plus acetic acid, butyl butyrate plus acetic acid, and isobutanol plus acetic acid (Table 1). Numbers of V. pen-
Table 1. Percentages (mean \pm SE) of worker yellowjackets captured in traps baited with heptyl butyrate (HB), butyl butyrate $(B B)$, and isobutanol (IB) with and without a $0.5 \%$ acetic acid solution (AA)

\begin{tabular}{lccc}
\hline \hline Treatment & V. germanica & V. pensylvanica & V. atropilosa \\
\hline Control & 0 & 0 & 0 \\
HB & $3.0 \pm 1.1 \mathrm{a}$ & $16.7 \pm 2.3 \mathrm{~b}$ & $42.6 \pm 3.9 \mathrm{~b}$ \\
$\mathrm{HB}+\mathrm{AA}$ & $7.8 \pm 1.7 \mathrm{a}$ & $44.5 \pm 3.4 \mathrm{~d}$ & $44.5 \pm 4.5 \mathrm{~b}$ \\
$\mathrm{BB}$ & $4.5 \pm 1.0 \mathrm{a}$ & $3.1 \pm 0.8 \mathrm{a}$ & $3.8 \pm 0.8 \mathrm{a}$ \\
$\mathrm{BB}+\mathrm{AA}$ & $17.6 \pm 4.0 \mathrm{a}$ & $14.1 \pm 2.3 \mathrm{~b}$ & $3.9 \pm 0.9 \mathrm{a}$ \\
$\mathrm{IB}$ & $3.4 \pm 1.0 \mathrm{a}$ & $0.9 \pm 0.3 \mathrm{a}$ & $0.8 \pm 0.5 \mathrm{a}$ \\
$\mathrm{IB}+\mathrm{AA}$ & $63.8 \pm 6.8 \mathrm{~b}$ & $20.5 \pm 3.1 \mathrm{c}$ & $4.2 \pm 1.2 \mathrm{a}$ \\
\hline
\end{tabular}

Percentages are based on block totals. Totals of $946 \mathrm{~V}$. germanica, $6,695 \mathrm{~V}$. pensylvanica, and $556 \mathrm{~V}$. atropilosa workers were captured in this experiment. Means in a column followed by the same letter are not significantly different at the 0.05 level by the Tukey test.

sylvanica captured in traps baited with isobutanol plus acetic acid were significantly greater than those captured in traps baited with isobutanol and were comparable to numbers captured in traps baited with heptyl butyrate only. However, the most $V$. pensylvanica were captured in traps baited with heptyl butyrate plus acetic acid. Large numbers of V. atropilosa were captured in traps baited with heptyl butyrate or heptyl butyrate plus acetic acid (Table 1). There was no difference in numbers of $V$. atropilosa trapped with heptyl butyrate with or without acetic acid.

Comparisons of Doses of Heptyl Butyrate and of Isobutanol. There was a positive relationship between doses of heptyl butyrate with $0.5 \%$ acetic acid and percentages of $V$. pensylvanica captured $(Y=6.45 \times$ $0.23 X), V$. germanica captured $(Y=10.6 \times 0.14 X)$, and $V$. atropilosa captured $(Y=2.9 \times 0.21 X)$ (Table 2$)$. Nearly no $V$. atropilosa were captured in traps baited with acetic acid and the zero dose of heptyl butyrate (Table 2).

For the high-dose series of isobutanol (Table 2), a positive relationship was not demonstrated between doses of isobutanol and captures of $V$. germanica or captures of $V$. pensylvanica. For the low-dose series (Fig. 1), a positive relationship was demonstrated between doses of isobutanol and captures of $V$. germanica $\left(r^{2}=0.82, t=2.87, \mathrm{df}=4, P=0.046, Y=11.0\right.$ $\times 1.1 X)$ and $V$. pensylvanica $\left(r^{2}=0.93, t=5.17, \mathrm{df}=\right.$ $4, P=0.0007, Y=9.4 \times 1.4 X)$. Numbers of $V$. atropilosa captured were not sufficient for statistical comparisons in these experiments.

Comparison of Concentrations of Acetic Acid. There was not a significant relationship between acetic acid concentration and captures of worker $V$. germanica when tested with heptyl butyrate (Table 3) $\left(r^{2}=-0.72, t=2.08, \mathrm{df}=5, P=0.11\right)$. Percentages of $V$. germanica captured were lower at the 2 highest acetic acid concentrations tested (1 and $2 \%)$ than at other concentrations, indicating a possible repellent effect. Similarly, there was not a significant relationship between captures of worker $V$. pensylvanica in traps and acetic acid concentration when traps were baited with acetic acid and heptyl butyrate (Table 3 ) $\left(r^{2}=-0.69, t=2.10, \mathrm{df}=5, P=0.10\right)$. At the highest concentration of acetic acid (2\%), captures of worker 
Table 2. Mean percentages $( \pm \mathrm{SE})$ of worker yellowjackets captured in traps baited with $0.5 \%$ acetic acid in the drowning solution and different doses of either heptyl butyrate or isobutanol in mineral oil in polyethylene caps

\begin{tabular}{|c|c|c|c|c|c|}
\hline $\begin{array}{l}\text { Percent in } \\
\quad 1 \mathrm{ml}\end{array}$ & \multicolumn{3}{|c|}{ Heptyl butyrate } & \multicolumn{2}{|c|}{ Isobutanol } \\
\hline 0 & $9.0 \pm 1.9$ & $1.6 \pm 0.4$ & $0.2 \pm 0.2$ & $4.7 \pm 0.7$ & $5.7 \pm 0.8$ \\
\hline 25 & $14.3 \pm 3.3$ & $13.3 \pm 1.1$ & $9.1 \pm 2.3$ & $19.1 \pm 2.3$ & $20.4 \pm 2.0$ \\
\hline 50 & $17.9 \pm 3.2$ & $24.9 \pm 1.8$ & $24.9 \pm 3.4$ & $13.6 \pm 2.0$ & $16.8 \pm 2.4$ \\
\hline 75 & $20.5 \pm 4.6$ & $24.7 \pm 2.2$ & $21.6 \pm 2.6$ & $22.9 \pm 2.1$ & $22.5 \pm 1.9$ \\
\hline$r^{2}$ & 0.98 & 0.91 & 0.95 & 0.58 & 0.70 \\
\hline df & 4 & 4 & 4 & 4 & 4 \\
\hline
\end{tabular}

Totals of $421 \mathrm{~V}$. germanica, $8,324 \mathrm{~V}$. pensylvanica, and $516 \mathrm{~V}$. atropilosa were captured in traps with heptyl butyrate, whereas $1,168 \mathrm{~V}$. germanica and $5,015 \mathrm{~V}$. pensyleanica were captured in traps with isobutanol.

V. pensylvanica were lower than in traps without acetic acid $(0 \%)$, indicating a possible repellent effect. Numbers of $V$. atropilosa captured in this experiment were not sufficient for statistical comparisons.

When concentrations of acetic acid were tested in combination with isobutanol, there was no significant relationship between acetic acid concentrations and captures of $V$. germanica $\left(r^{2}=0.34, t=0.89, \mathrm{df}=4\right.$, $p=0.51)$ or $V$. pensylvanica $\left(r^{2}=0.41, t=0.89, \mathrm{df}=\right.$ $4, P=0.42$ ). However, percentages of both $V$. pensylvanica and V. germanica workers captured in traps baited with isobutanol and acetic acid were much greater than in traps baited with isobutanol alone (Table 3). Numbers of V. atropilosa captured in this experiment were not sufficient for statistical comparisons.

- WESTERN

GERMAN

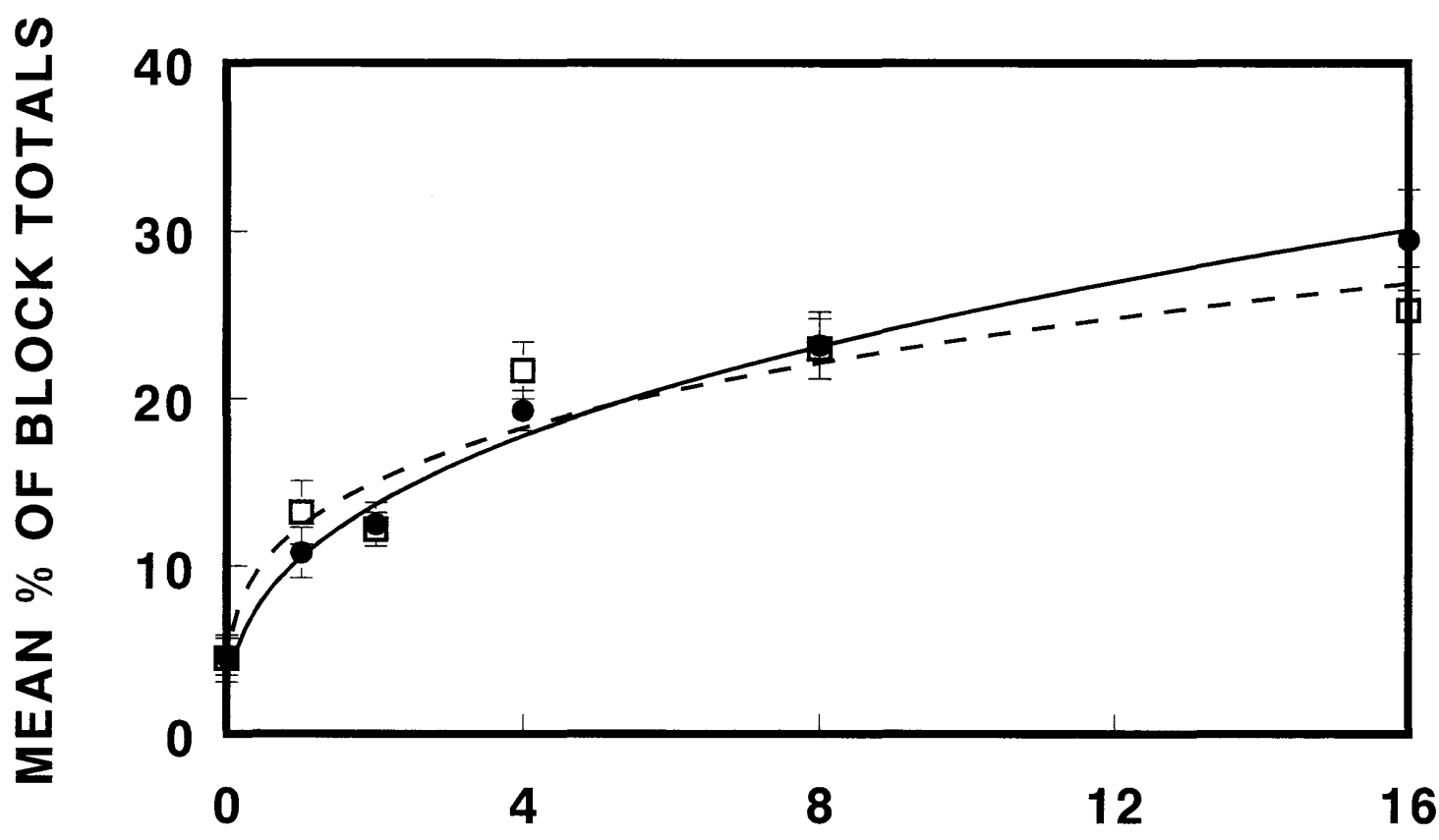

$\%$ IB IN MINERAL OIL

Fig. 1. Mean percentages ( $\pm \mathrm{SE}$ ) of wasps per block captured in traps baited with a $0.25 \%$ acetic acid solution and either $1 \mathrm{ml}$ of $1,2,4,8,12$, or $16 \%$ isobutanol (IB) in mineral oil. Wasps captured were $V$. pensylvanica (solid line) and $V$. germanica (dashed line). Totals of 3,464 V. germanica and 4,579 V. pensylvanica were trapped in this experiment. 
Table 3. Mean percentages $( \pm \mathrm{SE}$ ) of yellowjackets captured in traps baited with $1 \mathrm{ml}$ of $50 \%$ heptyl butyrate or $16 \%$ isobutanol and different concentrations of acetic acid in $200 \mathrm{ml}$ of water

\begin{tabular}{|c|c|c|c|c|}
\hline 0 & $18.2 \pm 4.3$ & $16.8 \pm 1.9$ & $7.6 \pm 1.0$ & $7.1 \pm 1.3$ \\
\hline 0.25 & $20.9 \pm 3.0$ & $21.0 \pm 2.1$ & $19.5 \pm 1.8$ & $19.5 \pm 1.8$ \\
\hline 0.50 & $29.2 \pm 4.6$ & $20.1 \pm 1.9$ & $18.9 \pm 1.1$ & $19.2 \pm 1.3$ \\
\hline 1.0 & $8.1 \pm 2.9$ & $14.6 \pm 1.2$ & $17.9 \pm 1.3$ & $19.3 \pm 1.4$ \\
\hline$r^{2}$ & -0.76 & -0.72 & 0.46 & 0.41 \\
\hline $\mathrm{df}$ & 4 & 4 & 4 & 4 \\
\hline
\end{tabular}

Total of $301 \mathrm{~V}$. germanica and 7,412 V.pensylvanica were captured with heptyl butyrate, whereas $8,822 \mathrm{~V}$. germanica and $4,783 \mathrm{~V}$.pensyltanica were captured in traps with isobutanol.

\section{Discussion}

These experiments demonstrated the attractiveness of a synthetic lure to worker $V$. germanica and its usefulness as a trap bait. The combination of acetic acid and isobutanol lured large numbers of $V$. germanica into traps, whereas acetic acid alone or isobutanol alone were weakly attractive. Thus, this bait combination is a potent chemical attractant for the German yellowjacket. Worker V. germanica also were trapped, but in lower numbers, with the combinations of acetic acid and butyl butyrate and acetic acid and heptyl butyrate. Workers of this species also respond to food materials such as molasses, jellies, and meats (Spurr 1995, 1996).

Vespula germanica is a major stinging pest in many countries and has been accidentally introduced around the world (Edwards 1976). Consequently, methods are needed both to detect and to control introduced populations. In the United States, it has been introduced on both coasts and has subsequently spread into much of the northeast and eastern Midwest as well as the Pacific coastal states (Morse et al. 1977, MacDonald et al. 1980, MacDonald and Akre 1984). A chemical attractant composed of acetic acid and isobutanol should provide a useful lure for detection and possibly localized control of $V$. germanica, if it is used in a suitable trap or incorporated into an artificial bait as suggested by Ross et al. (1984).

Both $V$. germanica and $V$. pensylvanica are wellknown for their scavenging foraging habits, which greatly contribute to their pest status (Akre et al. 1980). Thus, the attraction of these wasps to the combination of acetic acid and isobutanol is probably a food-finding behavior. Both chemicals were isolated from headspace over fermented molasses solutions and acetic acid is a well known microbial fermentation product. Yellowjackets are attracted to and feed on sugar-rich materials (Duncan 1939, Spurr 1996).

The attractiveness of carbohydrate baits to honeybees, Apis mellifera L., is of concern when trapping yellowjacket wasps (Spurr 1996). Because several of these chemicals that are attractive to yellowjackets were isolated from fermented sweet baits, the possibility of their attractiveness to honeybees is of con- cern. During the course of these tests, honeybees were not captured in traps. However, honeybees were not generally present in the area during the course of these experiments and additional testing should be conducted in locations with abundant bees. Bumblebees (Bombus spp.) also were not captured in traps during these studies.

Vespula pensylvanica workers also were attracted to the combination of isobutanol and acetic acid in significant numbers, as well as to heptyl butyrate and combinations of heptyl butyrate or butyl butyrate with acetic acid. Results of the tests of doses of isobutanol or heptyl butyrate indicated weak attraction of $V$. pensylvanica to acetic acid alone. This work indicates that $V$. pensylvanica are attracted to isobutanol and acetic acid and that acetic acid may synergize or enhance attraction of western yellowjackets to butyl butyrate or heptyl butyrate. Worker V. pensylvanica are attracted to butyl butyrate and heptyl butyrate, as well as to octyl butyrate (Davis et al. 1969, 1972). The strong enhancement by acetic acid of $V$. pensylvanica attraction to heptyl butyrate in the 1st experiment was contrasted by the lack of any positive effect of acetic acid in the later comparison of acetic acid concentrations combined with a heptyl butyrate lure. The latter experiment was conducted late in the season in fruit orchards with abundant decomposing fruit on the ground. Perhaps such food sources compete with trap lures and confound wasp responses to acetic acid. This discrepancy warrants further investigation.

These experiments indicated that $1 \mathrm{ml}$ of $4-100 \%$ isobutanol in mineral oil in a polyethylene cap provided strong attractiveness to $V$. germanica and to $V$. pensylvanica. The response of $V$. pensylvanica to heptyl butyrate with acetic acid was strong for the 3 highest heptyl butyrate doses tested ( $1 \mathrm{ml}$ of 50,75 , or $100 \%$ in mineral oil). Concentrations of acetic acid required for optimum captures of $V$. pensylvanica or $V$. germanica were not indicated by these test results, although 1 and $2 \%$ concentrations were clearly too high. These doses and methods of formulation together provide a highly effective method for attracting both of these species of yellowjackets. 


\section{Acknowledgments}

Helpful suggestions to improve the manuscript were made by C. O. Calkins, A. Greene, H. C. Reed, and 2 anonymous reviewers. Technical assistance was provided by C. E. Bick, L. L. Biddick, P. S. Chapman, C. P. Fein, R. W. Hofstetter, and D. L. Larson. I thank P. Garza and R. Dart for use of their apple orchards.

\section{References Cited}

Akre, R. D., A. Greene, J. F. MacDonald, P. J. Landolt, and H. G. Davis. 1980. Yellowjackets of America North of Mexico. U.S. Dep. Agric. Handbook No. 552.

Christie, G. D. 1992. Non-toxic bait trapping for yellowjackets. Pest Control (May 1992): 30-32.

DataMost. 1995. StatMost statistical analysis and graphics. DataMost, Salt Lake, UT

Davis, H. G., G. W. Eddy, T. P. McGovern, and M. Beroza. 1967. 2,4-Hexadienyl butyrate and related compounds highly attractive to yellowjackets (Vespula spp.). J. Med. Entomol. 4: 29-34.

1969. Heptyl butyrate, a new synthetic attractant for yellowjackets. J. Econ. Entomol. 62: 1245.

Davis, H. G., R. J. Peterson, W. M. Rogoff, T. P. McGovern, and M. Beroza. 1972. Octyl butyrate, an effective attractant for the yellowjacket. Environ. Entomol, 1: 673 .

Davis, H. G., R. W. Zwick, W. M. Rogoff, T. P. McGovern, and M. Beroza. 1973. Perimeter traps baited with synthetic lures for suppression of yellowjackets in fruit orchards. Environ. Entomol. 2: 570-571.

Duncan, C. 1939. A contribution to the biology of North American vespine wasps. Stanford Univ. Publ. Biol. Sci. 8: 1-282.

Dymock, J. J., S. A. Forgie, and P. J. Wigley. 1991. The responses of German wasps, Vespula germanica, to ingestion of the microbial toxin, avermectin B1. Proc. N. Z. Weed Pest Control Conf. 44: 38-41.

Edwards, R. 1976. The world distribution pattern of the German wasp, Paravespula germanica (Hymenoptera: Vespidae). Entomol. Germanica 3: 269-271.

1977. Trapping wasps (Vespula spp) and bees (Apis mellifera) at a sweet factory. Proceedings, 8th International Congress, International Union for the Study of Social Insects. Center for Agricultural Publications, Wageningen, The Netherlands.

1980. Social wasps, their biology and control. Rentokil, East Grinstead, UK.

Grant, C. D., C. J. Rogers, and T. H. Lauret. 1968. Control of ground-nesting yellow jackets with toxic baits-a five year program. J. Econ. Entomol, 61: 1653-1656.

Greene, A., and D. M. Caron. 1980. Entomological etymology: the common names of social wasps. Ann. Entomol. Soc. Am. 26: 126-130.

Grothaus, R. H., H. G. Davis, W. M. Rogoff, J. A. Fluno, and J. M. Hirst. 1973. Baits and attractants for east coast yellowjackets, Vespula spp. Environ. Entomol. 2: 717-718.
Howell, J. O., T. P. McGovern, and M. Beroza. 1974. Attractiveness of synthetic compounds to some eastern Vespula species. J. Econ. Entomol. 67: 629-630.

Landolt, P. J. 1995. Attraction of Mocis latipes (Lepidoptera: Noctuidae) to sweet baits in traps. Fla. Entomol. 78: 523-530.

Landolt, P. J., and E. R. Mitchell. 1997. Attraction of tobacco budworm moths (Lepidoptera: Noctuidae) to jaggery, a palm sugar extract. Fla. Entomol. 80: 402-407.

MacDonald, J. F., and R. D. Akre. 1984. Range extension and emergence of subterranean nesting by the German yellowjacket, Vespula germanica, in North America (Hymenoptera: Vespidae). Entomol. News 95: 5-8.

MacDonald, J. F., R. D. Akre, and W. B. Hill. 1973. Attraction of yellowjackets (Vespula spp.) to heptyl butyrate in Washington State (Hymenoptera: Vespidae). Environ. Entomol. 2: 375-379.

MacDonald, J. F., R. D. Akre, and R. E. Keyel. 1980. The German yellowjacket (Vespula germanica) problem in the United States (Hymenoptera: Vespidae). Bull. Entomol. Res. Am. 26: 436-442.

McGovern, T. P., H. G. Davis, M. Beroza, J. C. Ingangi, and G. W. Eddy. 1970. Esters highly attractive to Vespula spp. J. Econ. Entomol. 63:1534-1536.

Morse, R. A., G. C. Eickwort, and R. S. Jacobson. 1977. The economic status of an immigrant yellowjacket, Vespula germanica (Hymenoptera: Vespidae) in the north-eastern United States. Environ. Entomol. 6: 109-110.

Perrott, D.C.F. 1975. Factors affecting use of mirex-poisoned protein baits for control of European wasp (Paravespula germanica) in New Zealand. N.Z. J. Zool. 2: 491508.

Ross, D. R., R. H. Shukle, and J. F. MacDonald. 1984. Meat extracts attractive to scavenger Vespula in eastern North America (Hymenoptera: Vespidae). J. Econ. Entomol. 77: 637-642.

Spurr, E. B. 1995. Protein bait preferences of wasps (Vespula vulgaris and V. germanica) at Mt. Thomas, Canterbury, New Zealand. N.Z. J. Zool. 22: 281-289.

1996. Carbohydrate bait preferences of wasps (Vespula vulgaris and V. germanica) (Hymenoptera: Vespidae) in New Zealand. N.Z. J. Zool. 23: 315-324.

Spurr, E. B., K. W. Drew, P.E.C. Read, and G. Elliott. 1996. The effectiveness of a sulfluramid concentrate mixed with canned sardine cat-food for control of wasps. Proceedings, 49th New Zealand Plant Protection Conference 1996: 132-136. New Zealand Plant Protection Society, Rotorua, New Zealand.

Wagner, R. E., and D. A. Reierson. 1969. Yellow jacket control by baiting. 1. Influence of toxicants and attractants on bait acceptance. J. Econ. Entomol. 62: 1192-1197.

Received for publication 9 December 1997; accepted 23 April 1998. 